\title{
青藏高原东缘两处高山树线交错带时空动态及其 建群种的生态学特征
}

\author{
周天阳 ${ }^{1,2,3}$ NARAYAN Prasad Gaire 廖礼涁 $^{1,2}$ 郑莉莉 2,5 王金牛 ${ }^{1,3,6 *}$ \\ 孙 建 $^{5}$ 魏彦强 ${ }^{7}$ 谢 雨 ${ }^{1}$ 吴 彦 ${ }^{1,3 *}$
}

${ }^{1}$ 中国科学院成都生物研究所, 成都 $610041 ;{ }^{2}$ 中国科学院大学, 北京 $101408 ;{ }^{3}$ 中国科学院山地生态恢复与生物资源利用重点实验室, 成都 610041 ; ${ }^{4}$ 特里布文大学中央环境科学院, 加德满都; ${ }^{5}$ 中国科学院地理科学与资源研究所, 北京 $100101 ;{ }^{6}$ 国际山地综合发展中心, 加德满都; ${ }^{7}$ 中国科学院西北 生态环境资源研究院, 兰州 $730000{ }^{8}{ }^{8}$ 中国科学院西双版纳热带植物园, 云南西双版纳 666303

摘 要 热量匮乏是高山树线的主要成因, 在全球变暖趋势下对高山树线及其建群种的生态学过程及特征的研究具有重要 意义。该文以青藏高原东缘的折多山和剪子弯山两处高山树线(海拔分别为 $4265 \mathrm{~m}$ 和 $4425 \mathrm{~m}$ )作为研究对象, 通过设置垂直样 带, 同时结合区域温度、降水的长时间序列分析, 探究两处树线的时空动态过程, 并明确了建群种冷杉(Abies spp.)的生态学特 征。结果表明: 1)折多山和剪子弯山区域的气温在过去 58 年均存在显著的上升趋势(分别上升了 0.72 和 $0.91{ }^{\circ} \mathrm{C}$ ), 而折多山和剪 子弯山区域降水均存在微弱的降低趋势。2)折多山的峨眉冷杉(A. fabri)龄级结构呈反J形, 剪子弯山的鳞皮冷杉(A. squamata) 龄级结构呈双峰形, 二者种群结构均相对稳定。3)在小尺度上, 种子扩散限制使得两处树线的冷杉聚集分布。在大尺度上, 折 多山峨眉冷杉亦呈聚集分布, 而剪子弯山鳞皮冷杉受生长环境以及种内或种间关系的影响呈随机分布。4)两处样地建群树种 的树高和基径均随海拔升高而降低, 位于树线交错带上部的冷杉均呈现树高生长大于径向生长的异速生长关系, 而位于样地 中、下部位的冷杉大部分呈等速生长关系。5)相比10年前, 折多山和剪子弯山的树线及树种线位置均无明显变化, 剪子弯山 鳞皮冷杉种群的树木密度亦无明显变化, 而折多山的树木个体数提高了约 $25 \%$; 相比 20 年前, 折多山和剪子弯山的树种线分 别上移了 50 和 $30 \mathrm{~m}$, 树线位置分别升高了 75 和 $40 \mathrm{~m}$, 树木个体数亦明显增加, 分别提高了约 $220 \%$ 和 $100 \%$ 。树线及其建群种在 较大时空尺度上主要受热量的控制, 而在较小时空尺度上受温度及生长环境共同作用的影响。

关键词 树线; 时空动态; 龄级结构; 异速生长; 海拔梯度

周天阳, Narayan PG, 廖礼涁, 郑莉莉, 王金牛, 孙建, 魏彦强, 谢雨, 吴彦 (2018). 青藏高原东缘两处高山树线交错带时空动态及其建群种的生态学特 征. 植物生态学报, 42, 1082-1093. DOI: 10.17521/cjpe.2018.0082

\section{Spatio-temporal dynamics of two alpine treeline ecotones and ecological characteristics of their dominate species at the eastern margin of Qinghai-Xizang Plateau}

ZHOU Tian-Yang ${ }^{1,2,3}$, NARAYAN Prasad Gaire ${ }^{4,8}$, LIAO Li-Bin ${ }^{1,2}$, ZHENG Li-Li $^{2,5}$, WANG Jin-Niu ${ }^{1,3,6 *}$, SUN-Jian ${ }^{5}$, WEI Yan-Qiang ${ }^{7}$, XIE Yu $^{1}$, and WU Yan ${ }^{1,3 *}$

${ }^{1}$ Chengdu Institute of Biology, Chinese Academy of Sciences, Chengdu 610041, China; ${ }^{2}$ University of Chinese Academy of Sciences, Beijing 101408, China; ${ }^{3}$ Key Laboratory of Mountain Ecological Restoration and Bioresource Utilization, Chinese Academy of Sciences, Chengdu 610041, China; ${ }^{4}$ Central Department of Environmental Science, Tribhuvan University, Kathmandu, Nepal; ${ }^{5}$ Institute of Geographic Sciences and Natural Resources Research, Chinese Academy of Sciences, Beijing 100101, China; ${ }^{6}$ International Center for Integrated Mountain Development, Kathmandu, Nepal; ${ }^{7}$ Northwest Institute of Eco-Environment and Resources, Chinese Academy of Sciences, Lanzhou 730000, China; and ${ }^{8}$ Xishuangbanna Tropical Botanical garden, Chinese Academy of Sciences, Xishuangbanna, Yunnan 666303, China

\footnotetext{
Abstract

Aims Temperature limit is the main cause of alpine treeline formation. Therefore, it is important to understand the response mechanisms of alpine treeline as well as their tree species under the global climate change. The present study focused on the spatio-temporal dynamics of treeline and ecological characteristics of the tree species in two treeline ecotones.

Methods Two vertical belt-transect plots were established in each treeline ecotone of the Zheduo Mountain and Jianziwan Mountain of the eastern Qinghai-Xizang Plateau. Top and bottom of each transects were lain between species line and forest line, respectively. Detailed information of each tree species treeline, including species name, latitude, longitude, height, age, base diameter, and coordinates, was recorded accordingly. 
Important findings The temperatures of the two research areas have increased during the past 58 years. The precipitation has decreased slightly in both the Zheduo Mountain and Jianziwan Mountain. The age structure of Abies fabri from the Zheduo Mountain and A. squamata from the Jianziwan Mountain showed a reversed "J" shape curve and a bimodal shape, respectively. Within the two transects, due to the limitation of seed diffusion, the dominate species showed aggregated distributions at the small scale. At the large scale, A. fabri was aggregated at the Zheduo Mountain, while A. squanmata of the Jianziwan Mountain was randomly distributed due to the impact of surrounding environmental factors. Both tree height and base diameter decreased with the increase of elevation. The fir trees (Abies spp.) at the upper part of the treeline ecotone presented an allometric growth, whose height growth rate was higher than that of base growth, while the relationships between height growth and base growth were isometric at almost mid and lower part of the treeline ecotone. Compared with 10 years ago, there was no significant change at the position of treeline and tree species line of the Zheduo Mountain and the Jianziwan Mountain, neither of the tree density in the Jianziwan Mountain. However, the number of trees in the Zheduo Mountain increased by about $25 \%$. Compared with 20 years ago, tree species lines of the Zheduo Mountain and Jianziwan Mountain were shifted upwards by 50 and $30 \mathrm{~m}$, respectively. Besides, their treeline positions were increased by 75 and $40 \mathrm{~m}$, respectively. Furthermore, the number of trees also increased significantly by $220 \%$ and $100 \%$, respectively. Therefore, the treeline and its constructive species are mainly affected by temperature at the large spatio-temporal scale, while influenced by temperature and ambient environment at the small spatio-temporal scale.

Key words treeline; spatio-temporal dynamics; age structure; allometric; altitude gradient

Zhou TY, Narayan PG, Liao LB, Zheng LL, Wang JN, Sun J, Wei YQ, Xie Y, Wu Y (2018). Spatio-temporal dynamics of two alpine treeline ecotones and ecological characteristics of their dominate species at the eastern margin of Qinghai-Xizang Plateau. Chinese Journal of Plant Ecology, 42, 1082-1093. DOI: 10.17521/cjpe.2018.0082

树线交错带是指林线到树种线的生态过渡带, 林线作为郁闭森林的分布上限, 树种线为树种幼苗 所能分布的最高海拔, 而树线则为树高达 $3 \mathrm{~m}$ 并具 有独立主茎的树团的平均海拔位置(Körner, 1998)。 目前, 学术界对高山树线成因的主流论断为由海拔 升高所导致的热量贵乏(Körner, 1998; Körner \& Paulsen, 2004; Wilmking et al., 2004)。同时也有学者 指出降水是树线形成的影响因素, 主要体现在春、 冬季水分不足导致树种叶和芽干化, 从而抑制了树 木生长(戴君虎和崔海亭, 1999)。此外, 地形因子、 种间关系以及建群树种的种子萌发也被认为是局部 区域树线的重要成因(Stevens \& Fox, 1991; Körner, 1998; Kim \& Lee, 2015)。随气候变暖的加剧, 近年 来全球低纬度区域高山树线位置存在明显的上升趋 势(Luckman \& Kavanagh, 2000; Wong et al., 2010), 然而Körner认为气候变暖并不足以解释全球范围内 的树线动态变化, 同时指出水分限制、养分平衡以 及碳分配关系亦是树线变化的重要影响因素 (Körner, 2017)。树线位置的变化将导致局地生态系 统结构与功能和地表生物地球化学循环的改变 (Körner, 2003; Batllori et al., 2009)。因此, 树线交错 带的时空动态是全球变化生态学研究的重要议题 (IPCC, 2014), 树线动态的研究不仅可以了解树木对
气候变暖的响应机制, 还能对其未来变化趋势做出 相应预测, 具有重要的生态学意义。

树线对气候变化的响应并非简单的线性关系, 根据Harsch等(2009)的研究, 气候变暖趋势下, 全球 166 个监测点自 1900 年来仅有 $52 \%$ 的树线位置显著 升高, 这表明树线动态还受到树线树种性状以及局 地环境等多种因素的综合影响。因此, 在树线研究 过程中系统科学地探究区域树线交错带内树种的生 态学特征至关重要, 这不仅有助于了解树种对局部 复杂环境的适应机制，还能提高对大尺度上树线空 间异质性的认知。树种的龄级结构及空间分布格局 作为基本生态学特征, 一个稳定种群的年龄结构通 常呈反 $\mathrm{J}$ 形, 具有稳定的出生率与死亡率。外部环境 及树种生理特性均会影响种群的出生率及死亡率, 进而改变种群年龄结构及其稳定性 (Knowles \& Grant, 1983), 根据树种龄级结构状况不仅可以了解 树线树种的更新状况, 并且能预测该种群未来的发 展趋势。种群空间格局由物种的生理特性、种间关 系及周围环境等多种因素共同决定，不同的分布类 型反映了种群的生活史特征, 展现出种群特有的生 长策略(Condit et al., 2000)。空间分布格局与空间尺 度有重要联系, 在小尺度上种群通常呈聚集分布, 而在大尺度呈随机或均匀分布(Stewart \& Rose, 
1990; 张金屯，1998)。树线交错带建群树种的空间 格局分析将有助于揭示其格局的动态变化过程及形 成原因。

海拔作为树种生长与分布的重要影响因素, 其 作用主要体现在对局地水热的重新分配。大量的研 究探讨了树种与海拔的关系, 但由于研究区域具体 环境的差异而使得结果略有差异, 但主要表现为高 海拔区域的树种生长受到低温抑制(Lloyd \& Fastie, 2002; 程伟等, 2005; 白登忠, 2012)。树种性状研究 过程中, 树高与基径间的相关生长关系受到了广泛 关注。二者是模型中的关键参数, 树高表征树木对 光资源的获取能力, 而基径则与树木机械支撑、水 分运输相关 (Falster \&Westoby, 2003; 李利平等, 2011; 杨晓东等, 2013)。异速生长分析作为树种个 体水平上生长模式的认识手段, 可揭示植物不同发 育阶段及异质环境下的生长策略(Niklas, 2005; 高 景等, 2016)。研究树高与基径间的关系及其随海拔 升高的变化规律, 可加深对树种生长策略及树线动 态机制的认识。

青藏高原拥有全球最丰富和海拔最高的树线, 并且受到的人为干扰较少, 在过去几十年, 青藏高 原升温趋势显著高于世界平均水平(Liu \& Chen, 2000; Shi et al., 2015)。因此, 该区域是开展高山树 线研究的“天然实验室”。现有的青藏高原树线的相 关研究表明, 气候变暖使树线树种密度有小幅度提 高, 同时树木死亡的风险也有一定程度的增加, 然 而树线对气候变暖的响应机制依然不明确, 树线位 置的变化也不尽相同(Liang et al., 2011, 2016; 王亚 锋等, 2017)。针对青藏高原区域树线交错带时空动 态的研究相对较少, 关于树线交错带内建群种生态 学特征的研究亦不多见。青藏高原东南缘属于低纬 度高海拔的特殊区域, 通过对该区域内的折多山及 剪子弯山两处高山树线开展实验, 本文探究目标如 下：1)树线交错带内建群种的生态学特征及其与生 长环境的响应机制, 2)树线交错带的时空动态及其
变化规律。从而了解气候变化对高山树线造成的影 响, 以期丰富对高山生命带格局及生态学过程的 理解。

\section{1 材料和方法}

\section{1 研究区概况}

研究样地位于四川省康定市的折多山(101.73 $\mathrm{E}, 30.05^{\circ} \mathrm{N}$; 海拔 $4400 \mathrm{~m}$ ) 及雅江县的剪子弯山 $\left(100.82^{\circ} \mathrm{E}, 30.02^{\circ} \mathrm{N}\right.$; 海拔4 $\left.500 \mathrm{~m}\right)$, 属于青藏高原 东南缘, 处于亚热带湿润季风区与青藏高原寒冷气 候的过渡带, 日照充足, 冬季干燥寒冷, 夏季湿润 凉爽, 雨热同季。康定县城附近(海拔2 $800 \mathrm{~m}$ )年平 均气温 $7.6{ }^{\circ} \mathrm{C}, 1$ 月平均气温 $-1.9{ }^{\circ} \mathrm{C}, 7$ 月平均气温 $15.8{ }^{\circ} \mathrm{C}$, 年降水量 $820 \mathrm{~mm}$, 主要集中在7-9月; 雅 江县城附近(海拔3 $950 \mathrm{~m}$ )年平均气温 $4.5{ }^{\circ} \mathrm{C}, 1$ 月平 均气温 $-4.2{ }^{\circ} \mathrm{C}, 7$ 月平均气温 $11.5{ }^{\circ} \mathrm{C}$, 年降水量 $640 \mathrm{~mm}$, 主要集中于7-9月。两处样地的土壤均为 暗棕壤, 土层厚度大致为 $10-50 \mathrm{~cm}$ 。两处样地主要 的乔木有冷杉属的峨眉冷杉(Abies fabri) 和鳞皮冷 杉(Abies squamata)、川西云杉(Picea likiangensis)和 四川红杉(Larix mastersiana), 灌木主要以毡毛栋叶 杜鹃(Rhododendron phaeochrysum var. levistratum) 为主, 主要的草本植物有高原毛莨 (Ranunculus tanguticus)、车前(Plantago asiatica)、早熟禾(Poa annua)和㢣芦(Veratrum nigrum)等。

\section{2 试验设计及样品采集}

2017年8月中旬对康定折多山和雅江剪子弯山 的树线交错带进行了样带调查, 分别沿着山体坚直 方向选定受人为干扰较少、地形较为平坦一致的研 究样地布设样带。以树种分布上限作为样带顶端, 样带的底端为郁闭森林的上限(即林线), 样带宽度 30-50 m, 具体长度依据样地内植物分布等适当调 整。将样带的长与宽设为二维坐标的 $X 、 Y$ 轴, 以便 对样带内树种个体标记定位, 将样带左上角记为坐 标原点, 并记录样带上下端的海拔及经纬度。折

表1 折多山和剪子弯山树线交错带样地概况

Table 1 The basic information of treeline ecotone of Zheduo Mountain and Jianziwan Mountain

\begin{tabular}{|c|c|c|c|c|c|}
\hline $\begin{array}{l}\text { 样地 } \\
\text { Plot }\end{array}$ & $\begin{array}{l}\text { 海拔 } \\
\text { Altitude (m) }\end{array}$ & $\begin{array}{l}\text { 经纬度 } \\
\text { Longitude and latitude }\end{array}$ & $\begin{array}{l}\text { 坡向 } \\
\text { Slope aspect }\end{array}$ & $\begin{array}{l}\text { 坡度 } \\
\text { Slope }\end{array}$ & $\begin{array}{l}\text { 主要树种 } \\
\text { Main species }\end{array}$ \\
\hline $\begin{array}{l}\text { 折多山 } \\
\text { Zheduo Mountain }\end{array}$ & $4210-4380$ & $101.73^{\circ} \mathrm{E}, 30.05^{\circ} \mathrm{N}$ & 正北 North & $27.5^{\circ}$ & $\begin{array}{l}\text { 峨眉冷杉、川西云杉、四川红杉 } \\
\text { Abies fabri, Picea likiangensis, Larix mastersiana }\end{array}$ \\
\hline $\begin{array}{l}\text { 剪子弯山 } \\
\text { Jianziwan Mountain }\end{array}$ & $4360-4520$ & $100.82^{\circ} \mathrm{E}, 30.02^{\circ} \mathrm{N}$ & $\begin{array}{l}\text { 西偏北 } 30^{\circ} \\
\text { North-west } 30^{\circ}\end{array}$ & $25.3^{\circ}$ & 鳞皮冷杉、四川红杉 Abies squamata, Larix mastersiana \\
\hline
\end{tabular}


多山样带大小为 $60 \mathrm{~m} \times 390 \mathrm{~m}$, 剪子弯山样带大小 为 $50 \mathrm{~m} \times 380 \mathrm{~m}$ 。分别对样带内的树木个体进行测 量, 记录每株树在样带内的坐标位置并用GPS记录 其经纬度, 树高大于 $3 \mathrm{~m}$ 的于 $1.3 \mathrm{~m}$ 处用胸径尺测量 胸径, 树高小于 $3 \mathrm{~m}$ 的测量其基径(地径), 并使用激 光测距仪测量树高, 较矮小的树木用卷尺测量树高 并记录。树龄采用树枝的分叉数计算, 一个分枝记 为一年, 主枝不明显则选最大数(Liang et al., 2011)。

\section{3 点空间格局分析方法}

本研究采用空间格局分析方法中的 $L(r)$ 函数对 两个样地内的优势种冷杉进行分析。 $L(r)$ 函数是由 $K(r)$ 函数修正得到, $K(r)$ 函数主要基于种群分布的二 维坐标信息, 对种群在多种空间尺度上进行分析, $K$ 值随着尺度的变化而变化。 $K(r)$ 函数公式如下:

$$
K(r)=\frac{A}{n^{2}} \sum_{i=1}^{n} \sum_{j=1}^{n} \frac{\operatorname{Ir}\left(u_{i j}\right)}{w_{i j}}(i \neq j)
$$

式中, $A$ 为样地总面积, $u_{i j}$ 为 $i 、 j$ 两个个体之间的距离, $n$ 为种群总数, $r$ 为大于 0 的数, 当 $u_{i j}<r$ 时, $\operatorname{Ir}\left(u_{i j}\right)=1$, 当 $u_{i j}>r$ 时, $\operatorname{Ir}\left(u_{i j}\right)=0, W_{i j}$ 是以点 $i$ 为圆心, 以 $u_{i j}$ 为半 径的圆周长与样地面积 $A$ 的比值, 可以消除边界效应。

为了在随机分布下保持方差稳定和结果有效, 引入了 $L(r)$ 函数, 公式如下:

$$
L(r)=\sqrt{\frac{K(r)}{\pi}-r}
$$

若 $L(r)=0$, 则在 $r$ 范围内呈随机分布; 若 $L(r)<$ 0 , 则在 $r$ 范围内呈均匀分布; 若 $L(r)>0$, 则在 $r$ 范围 内呈聚集分布(Ripley, 1977; 张金屯, 1998; 张璞进 等, 2017)。

\section{4 异速生长分析方法}

树高-径向生长关系采用 $y=a x^{b}$ 模型进行研究, 将两边取对数后 (以 10 为底数) 转化为 $\lg y=\lg a+$ $b \lg x, x$ 和 $y$ 为特征参数即径向生长和树高生长, $a$ 为 截距, $b$ 为斜率, 当 $b=1$ 时即为等速生长关系, 否则 为异速生长关系。不同海拔梯度的树木相关生长斜 率无显著差异时, 进一步检验它们之间是否存在截 距漂移(共轴但截距不同)和共轴漂移(截距相同且存 在共轴漂移)。若斜率 $b$ 存在显著差异则呈现完全不 同的生长关系。分析方法采用标准化主轴估计(SMA) 法(Warton et al., 2006)。

\section{5 数据处理}

由于观测样地附近没有长序列的气象观测站点， 且折多山和剪子弯山都处于青藏高原东缘的高山区,
在高海拔区利用远距离的气象站点替代局地气候观 测，其代表性较差。因此，本文选择了陆面地表同化 数据, 以使用较广的环境数据分析中心(CEDA)长 序列再分析资料CRUTS 4.01 (http://catalogue.ceda. ac.uk/intro)作为地面气候的分析基础。该数据集包 括了日平均气温、日降水量、日总辐射等气候数据, 数据范围覆盖全球中低纬度, 空间分辨率为 $0.5^{\circ} \times$ $0.5^{\circ}$, 时间为1960-2017年, 能基本满足本研究的趋 势分析需求。点空间格局分析采用R 3.4.1软件中的 “ads”包(Pelissier \& Goreaud, 2015)进行计算, 空间 尺度采用0-100 m, 经过99次的Monte Carlo模拟得 到 $99 \%$ 的置信区间; 同时使用“smatr”包(Warton et al., 2012)对树木径向及高生长进行异速分析。树线 时空模拟参照前人的研究来开展(Liang et al., 2011; 苒飞等, 2014), 根据树龄与树高的回归关系, 将目 前样地中所有树木的年龄往前逆推 10 和 20 年, 找出 树高大于 $3 \mathrm{~m}$ 的树的位置, 以此确定过去的树线位 置。作图在R 3.4.1软件及Origin 2016中完成。

\section{2 结果和分析}

\section{1 两处样点的温度与降水时间序列}

本文利用逐日的平均气温和逐日降水量, 分别 计算了1961-1970和2010-2017年的年平均气温和年 降水量, 并利用两个阶段的差值来分析气候变化的 绝对量(图1)。

从同化数据的结果来看, 折多山和剪子弯山两 处样地在过去的 58 年间, 其气候变暖趋势明显, 整 个四川省及其周边地区都表现出明显的升温趋势。 两处样地的年平均气温分别增加了 $0.72{ }^{\circ} \mathrm{C}$ (折多 山)和 $0.91{ }^{\circ} \mathrm{C}$ (剪子弯山), 增温幅度上, 折多山小 于剪子弯山。从降水量变化来看, 重庆及四川盆地 周边地区基本以降水量增加为主, 而四川省西南部 以降水量减少为主。两处样地中, 折多山降水量减 少 $3.3 \mathrm{~mm}$, 而剪子弯山减少 $5.0 \mathrm{~mm}$, 两者的差别较 小。总体来看, 这两个地区在过去的 58 年间, 气候变 化总趋势以暖干化为主, 暖化趋势明显, 但降水减 少的趋势不太显著。

\section{2 树种龄级结构}

折多山样地中分布有 3 个树种, 即峨眉冷杉、川 西云杉和四川红杉, 数量分别为 $130 、 7$ 和 28 , 峨眉冷 杉为该样地的主要物种，其数目占总数的 $78.79 \%$; 剪子弯山样地中只有鳞皮冷杉和川西云杉两个物种, 
数量分别为 79 和 16 , 其中鳞皮冷杉数量占总数的 $83.16 \%$ 。此外, 两处样地均伴生有少量杜鹃灌木。 树木龄级分析如图2。折多山样地中, 峨眉冷杉在 11-15龄级范围内的树木数量最多 (30株), 占其总数 的 $23.08 \%$, 峨眉冷杉龄级结构呈近似反形, 属于稳 定种群; 四川红杉在16-20龄级内的数量最多(8株), 占其总数的 $28.57 \%$, 而四川红杉呈近似单峰形。剪 子弯山样地中鳞皮冷杉在 16-20龄级内的数量最多 (18株), 占鳞皮冷杉总数的 $22.78 \%$, 龄级结构大致 呈双峰形。

\section{3 树木基径和树高沿海拔梯度的变化}

两处样地的树木基径与树高均沿海拔的升高而 呈现显著的下降趋势(图3, $p<0.001$ )。树高、树基径
与海拔关系的斜率绝对值在剪子弯山均大于它们在 折多山的斜率绝对值, 表明在剪子弯山的单位海拔 变化对树高及树基径的影响要大于折多山单位海拔 变化对树高及基径的影响。

\section{4 不同海拔梯度冷杉的生长特征分析}

将两处样带分别沿 $Y$ 轴按每 $100 \mathrm{~m}$ 为一个梯度 划分为 4 个梯度, 研究每个梯度内建群种冷杉的径 向生长与树高生长间的关系(表2)。结果表明，折多 山样地中海拔梯度最高段的峨眉冷杉, 其径向生长 和树高生长间呈显著的异速关系 $(p<0.001)$, 即树 高生长速率 $>$ 径向生长速率; 其余 3 个海拔梯度上均 为等速生长关系; 4 个梯度间相关生长斜率存在显 著差异 $(p<0.05)$, 具体为第一梯度 $>$ 第三、四梯
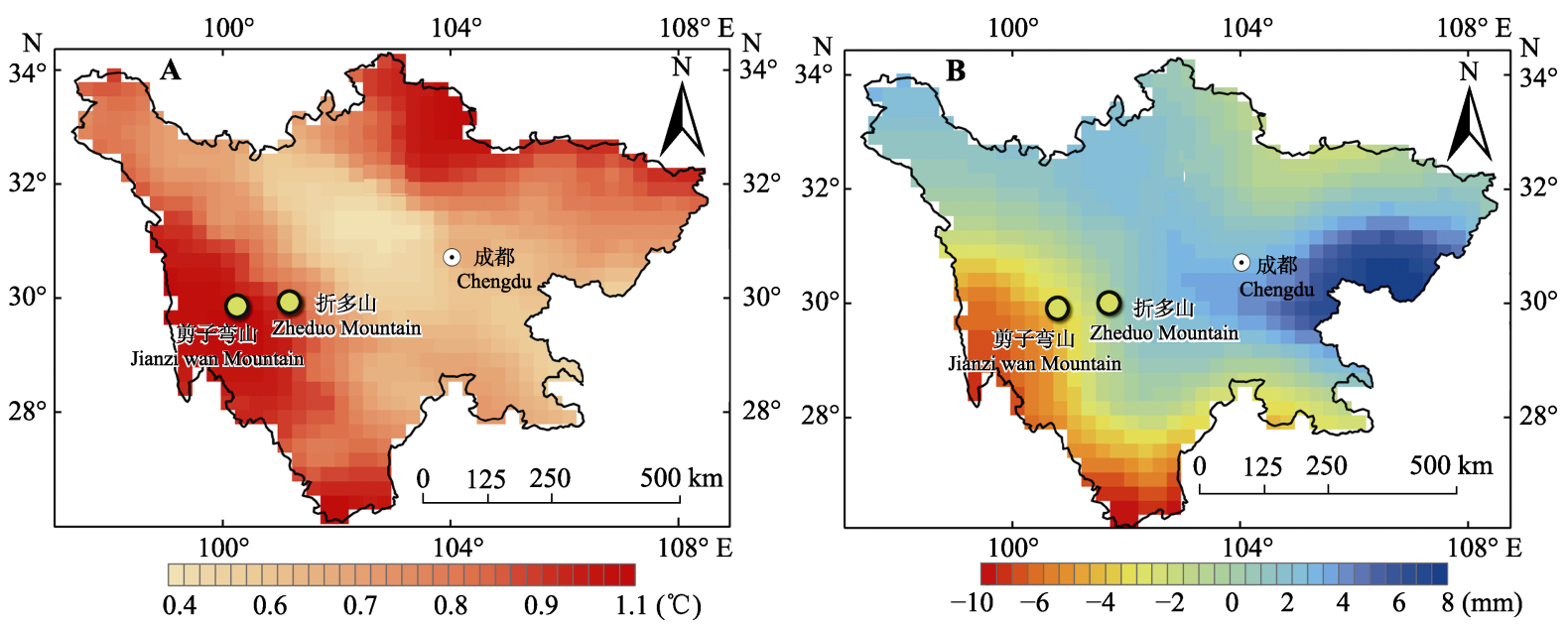

图1 2010-2017年与1961-1970年的差值。A, 年平均气温。 B, 年降水量。

Fig. 1 The difference value map between 2010-2017 and 1961-1970. A, Annual mean temperature. B, Annual precipitation.
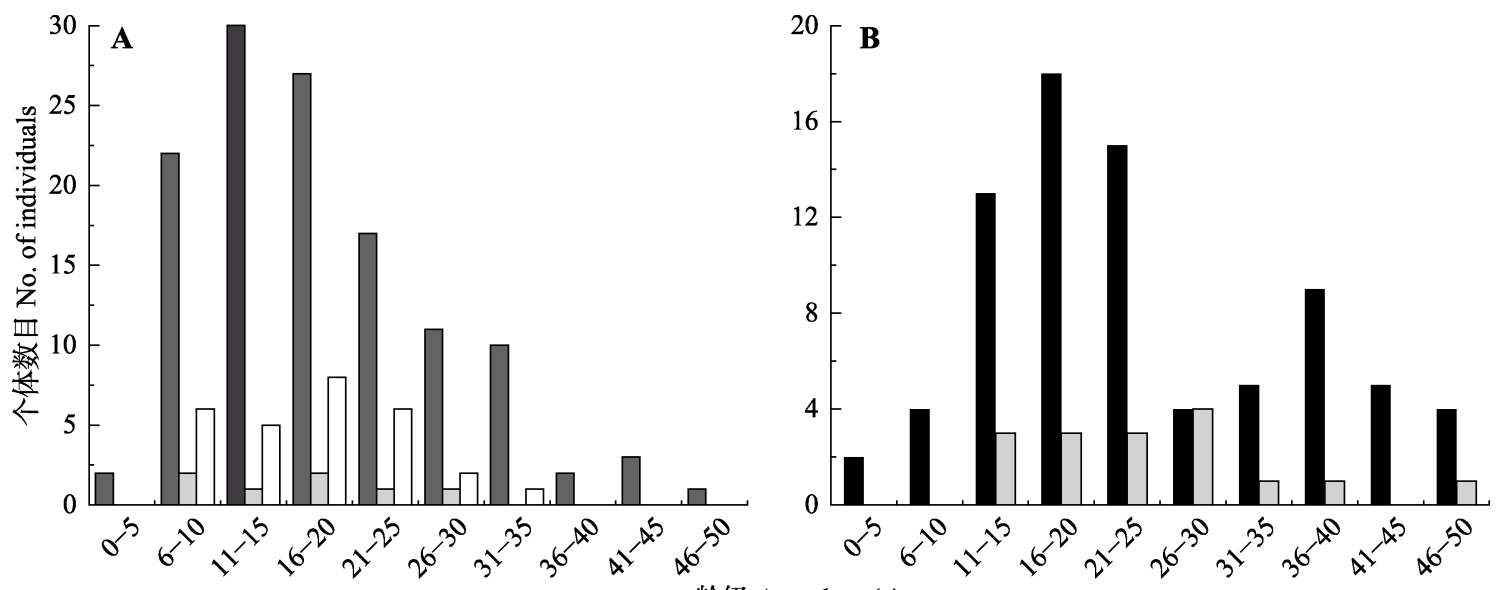

峨眉冷杉 Abies fabri

鳞皮冷杉 Abies squamata

川西云杉 Picea likiangensis

四川红杉 Larix mastersiana

图2 折多山(A)及剪子弯山(B)样地树种龄级结构。

Fig. 2 Age structure of treeline-forming species at treeline in the Zheduo Mountain (A) and Jianziwan Mountain (B). 

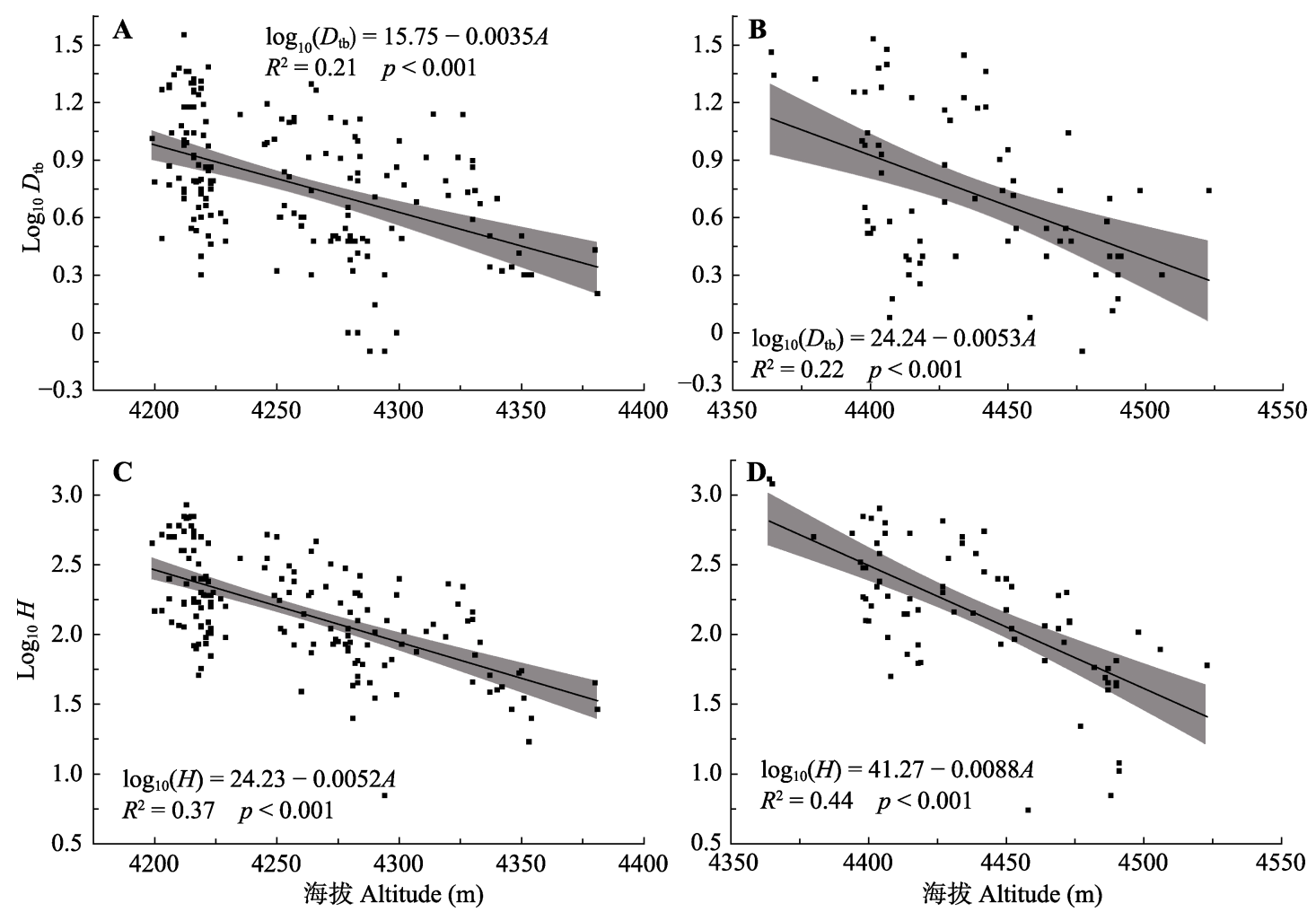

图3 折多山 $(\mathbf{A}, \mathbf{C})$ 与剪子弯山 $(\mathbf{B}, \mathbf{D})$ 的树高 $(H)$ 、基径 $\left(D_{\mathrm{tb}}\right)$ 与海拔 $(A)$ 的关系。

Fig. 3 The relationships of tree height $(H)$, base diameter $\left(D_{\mathrm{tb}}\right)$ and altitude $(A)$ in Zheduo Mountain $(\mathbf{A}, \mathbf{C})$ and Jianziwan Moun$\operatorname{tain}(\mathbf{B}, \mathbf{D})$.

表2 折多山与剪子弯山冷杉径向生长与高生长间的关系

Table 2 The correlation between the growth of height and base diameter in Zhedou Mountain and Jianziwan Mountain

\begin{tabular}{|c|c|c|c|c|c|}
\hline $\begin{array}{l}\text { 样点 } \\
\text { Plot }\end{array}$ & $\begin{array}{c}Y \text { 轴 } \\
Y(\mathrm{~m})\end{array}$ & $R^{2}$ & $p$ & $\begin{array}{c}\text { 斜率 }(95 \% \text { 置信区间) } \\
\text { Slope ( } 95 \% \text { confidence interval) }\end{array}$ & $\begin{array}{c}\text { 等速生长检验 } \\
\text { Test of isometry } p\end{array}$ \\
\hline \multirow[t]{4}{*}{ 折多山 Zheduo Mountain } & $<100$ & 0.80 & $<0.001$ & $1.64(1.30,2.08)^{\mathrm{a}}$ & $<0.001$ \\
\hline & $100-200$ & 0.54 & $<0.001$ & $0.72(0.51,1.00)^{\mathrm{c}}$ & 0.053 \\
\hline & $201-300$ & 0.72 & $<0.001$ & $1.15(0.98,1.34)^{\mathrm{b}}$ & 0.08 \\
\hline & $>300$ & 0.52 & $<0.001$ & $1.12(0.90,1.34)^{\mathrm{b}}$ & 0.296 \\
\hline \multirow[t]{4}{*}{ 剪子弯山 Jianziwan Mountain } & $<100$ & 0.75 & $<0.001$ & $1.53(1.21,1.93)^{\mathrm{a}}$ & $<0.001$ \\
\hline & $100-200$ & 0.85 & $<0.001$ & $0.99(0.80,1.22)^{\mathrm{b}}$ & 0.92 \\
\hline & $201-300$ & 0.80 & $<0.001$ & $0.83(0.63,1.10)^{\mathrm{b}}$ & 0.18 \\
\hline & $>300$ & 0.90 & $<0.001$ & $0.85(0.74,0.98)^{\mathrm{b}}$ & 0.028 \\
\hline
\end{tabular}

不同小写字母表示存在差异显著。

Different lowercase letters indicate significant difference.

度 $>$ 第二梯度。剪子弯山的结果与折多山的结果相

似，最高梯度呈显著的异速关系 $(p<0.001)$, 即高 生长速率 $>$ 径向生长速率, 而最低梯度呈现显著径 向生长速率 $>$ 高生长速率的关系 $(p<0.05)$, 其余两 个梯度均呈等速生长状态。建群种冷杉的相关生长 斜率在两个样地的 4 个梯度间均存在显著差异, 因 此不再进行截距漂移和共轴漂移检验。

\section{5 建群种空间分布及树线时空动态}

对两个样地的建群种冷杉进行点空间格局分析, 结果见图4。研究表明样地间的分布格局有明显的差
异，折多山样地的峨眉冷杉在小尺度范围内呈聚集 分布，随着尺度的增加，聚集程度有所提高; 剪子 弯山样地的鳞皮冷杉在小尺度范围内同样呈现聚集 分布，小于 $60 \mathrm{~m}$ 的范围内聚集程度呈现波动状态， 在更大的尺度上 $(>60 \mathrm{~m})$ 则呈现出随机分布格局, 表明其分布格局与尺度大小密切相关。

利用树高与树龄间的关系对样地树线分布进行 模拟分析 $(10$ 年前及 20 年前), 具体树高-树龄模型见 表3。建立的两个样地的树高-树龄模型均较好 $(p<$ $0.001, R^{2}$ 分别为 0.68 和 0.71$)$, 能较准确地模拟前 10 
表3 折多山与剪子弯山树高 $(H)$ 与树龄 $(a)$ 的回归模型

Table 3 The regression model of tree height $(H)$ and tree age $(a)$

\begin{tabular}{llll}
\hline 样地 & $\begin{array}{l}\text { 回归方程 } \\
\text { Regression equation }\end{array}$ & $R^{2}$ & $p$ \\
Plot & $H=34.80 \mathrm{e}^{0.079 a}$ & 0.68 & $<0.001$ \\
\hline 折多山 Zheduo Mountain & $H=14.38 \mathrm{e}^{0.087 a}$ & $0.71<0.001$ \\
\hline 剪子弯山 Jianziwan Mountain & $H$ & $<$
\end{tabular}

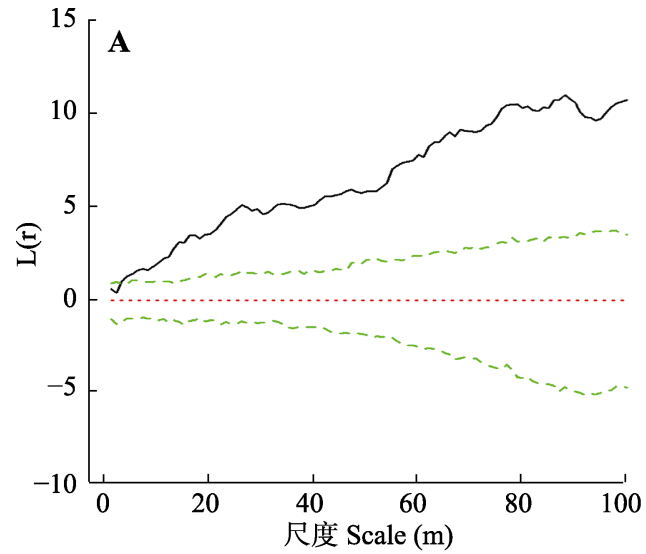

至20年的情况。模拟结果见图5，由模拟分布图可以 看出, 目前折多山样地的树线海拔约为 $4275 \mathrm{~m}$, 树 种线海拔约为 $4380 \mathrm{~m}$, 样地最下端为郁闭森林; 与 10年前相比，目前该样地的树线及树种线位置无明 显变化，而树木数量提高了约 $25 \% ; 20$ 年前树线及

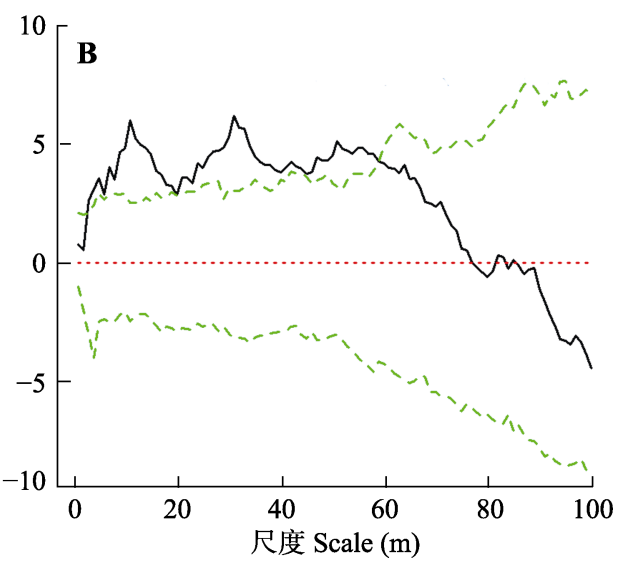

图4 折多山(A)及剪子弯山(B)样地点空间格局分析。两条绿线为拟合的置信区间，黑线为模拟结果。

Fig. 4 Point pattern analyses for the Zheduo Mountain (A) and Jianziwan Mountain (B). The two green lines are the confidence intervals for the fitting, and the solid line is from the simulation.

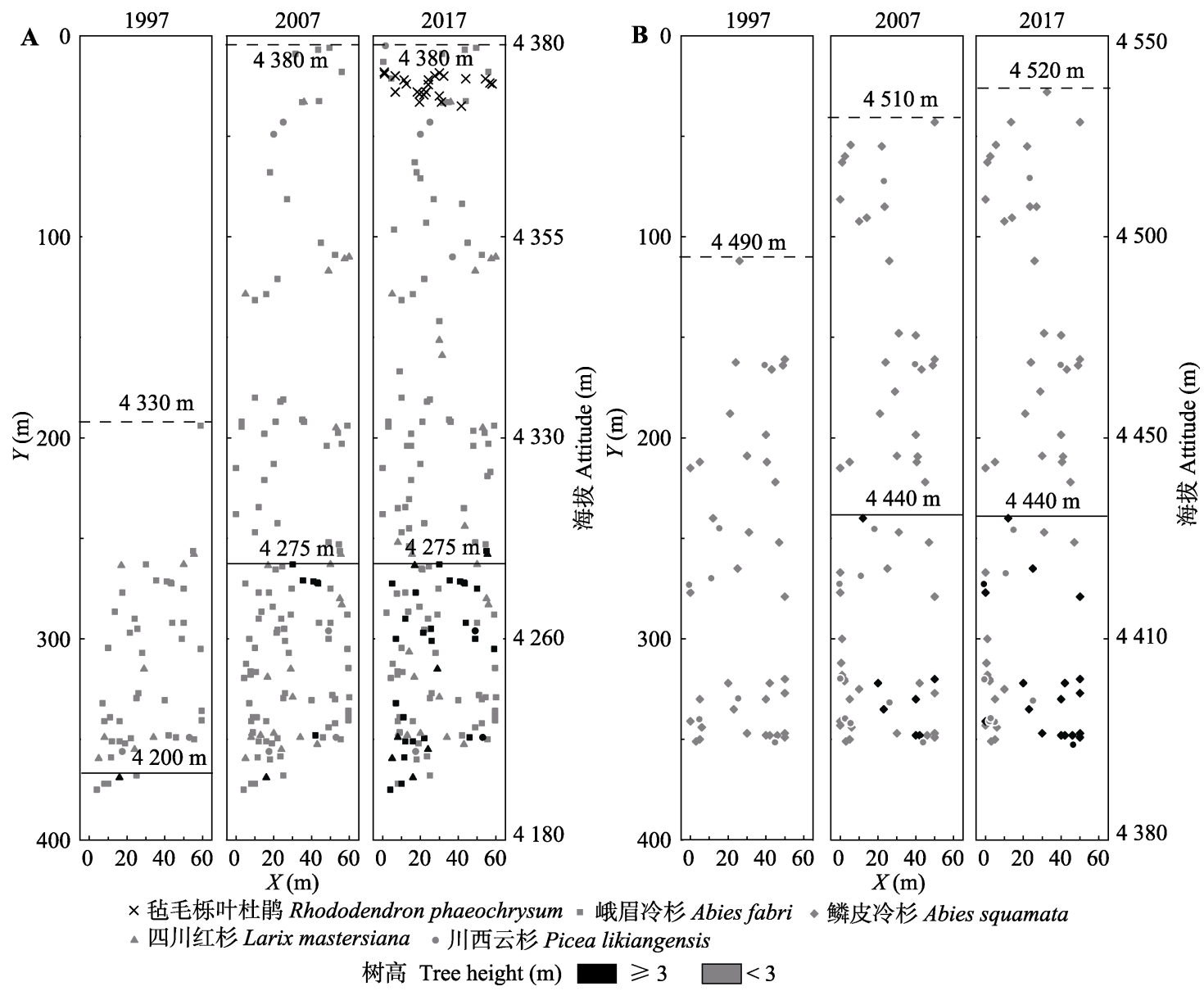

图5 折多山(A)及剪子弯山(B)样地树线时空模拟。图中黑线为树线, 虚线为树种线。

Fig. 5 The spatio-temporal pattern of treeline dynamics in the Zheduo Mountain (A) and Jianziwan Mountain (B). The solid line is the position of treeline and the dash line is tree species line.

www.plant-ecology.com 
树种线的海拔分别约为 $4200 \mathrm{~m}$ 和 $4330 \mathrm{~m}$, 与目前 相比, 二者分别提高了 $75 \mathrm{~m}$ 和 $50 \mathrm{~m}$, 而树木个体数 (54株)仅为目前的 $1 / 3$ 。剪子弯山样地目前的树种线 位于海拔4 $520 \mathrm{~m}$ 处, 树线位于海拔约 $4440 \mathrm{~m}$ 处; 10 年前该样地的树木个体数、树线及树种线位置与目 前基本保持一致; 20 年前树木个体数(47株)仅为目 前的一半, 树种线位于 $4490 \mathrm{~m}$ 处, 而树线位于样地 下方具体海拔无法确定, 相比当前样地内树种线上 升了 $30 \mathrm{~m}$ ，树线位置至少爬升了 $40 \mathrm{~m}$ 。

\section{3 讨论}

\section{1 高山树线的树种龄级结构}

种群的龄级结构是指不同年龄层级的个体在种 群内的分布情况, 是种群重要的特征之一(靳虎甲 等, 2012)。此指标不仅反映出种群目前的生长状态, 也可以了解种群过去的结构, 并对未来变化趋势做 出预测(谢宗强等, 1999)。本研究中, 折多山峨眉冷 杉龄级结构表现为低龄级树木较多, 高龄级树木较 少, 属于稳定型种群。同时, 其幼苗数量比例较高, 表明种群更新状态较好。四川红杉作为伴生种呈现 出与峨眉冷杉相似的龄级结构, 相比于峨眉冷杉种 群, 其幼苗数量比例较低, 表明其更新缓慢。可能是 四川红杉作为阳生性植物, 其种子的萌发需要一定 的光照, 随着样地内峨眉冷杉种群的增长阻碍了四 川红杉幼苗对于光资源的获取; 同时, 样地内的低 温环境及树木对土壤养分、水分竞争压力的增大在 一定程度上也不利于四川红杉幼苗的生长, 作为先 锋树种的四川红杉逐渐被喜阴耐寒的峨眉冷杉所取 代。川西云杉在该样地中的数量相对更少, 无明显 规律的龄级结构, 同时低龄级树木较少, 因此该树 种存在逐渐衰退的趋势。两处样地的冷杉龄级结构 存在一定的差异, 剪子弯山的鳞皮冷杉龄级结构呈 现中间低, 两边高的状态, 其幼苗数量比例较高, 表明该种群更新状态较好。种群龄级结构受众多因 素的影响, 比如林分密度、种间关系土壤理化性质 及地形因子等(矢佳昱等, 2017), 剪子弯山样地中的 鳞皮冷杉中间龄级处(26-35年)出现了波谷, 可能与 人为干扰(放牧及道路铺设等)等因素有关。

\section{2 高山树线交错带不同海拔梯度冷杉生长特征}

树线位置移动反映了树线在种群水平上的变化, 而树木生长特征指示了树线在个体水平上的变化 (王亚锋和梁尔源, 2012)。总体来看, 两个样地内冷
杉种群的树高及基径均随海拔的升高而降低，这与 大多数研究结果相似(程伟等, 2005; 白登忠, 2012)。 主要原因是树高、基径与气温呈正相关关系, 海拔 升高气温逐渐下降，低温胁迫下树种生长受到抑制， 植物形成的新细胞及组织生长速率均较低, 因此高 海拔地段的树木形态普遍矮小 (Körner, 2004; 程伟 等, 2005)。此外，从树龄方面考虑，高海拔梯度内大 部分为形态矮小的幼树, 而树龄较大的树大多分布 在中、低海拔梯度内, 其树高及基径自然也相对较 大。植物不同组织或部分间相关生长关系的变化表 征了其在异质环境下的生长策略的差异及表型可塑 性(高景等, 2016)。关于树木径向生长与树高生长之 间的关系，两处样地的最高海拔梯度内均呈现显著 的异速生长关系, 即高生长速率大于径向生长速率, 相关生长斜率均显著高于其他梯度内。这主要是由 树木生理特性决定的, 最高海拔梯度中大部分为冷 杉幼苗, 树龄显著低于其他梯度 $(p<0.05)$ 。幼苗在 周围灌丛的庇护下受到的外界干扰相对较小, 生长 早期偏向把更多资源投入高生长, 这将有助于增强 其对光资源的捕获效率(李国春等, 2017)。随着海拔 降低, 两处样地树种的相关生长斜率逐渐下降, 树 木开始呈现等速生长状态。除了生理因素外温度起 到了较大作用, 有研究表明树木径向生长对气温变 化非常敏感, 径向生长速率在林线以上海拔升高过 程中几乎呈线性下降(Körner, 2017)。值得注意的是, 折多山其余海拔梯度段内树种高生长-径向生长均 呈等速生长状态，而剪子弯山样地最低海拔段内径 向生长速率显著大于树高生长速率。本研究中, 高 海拔幼龄冷杉采取竞争性生长策略, 而树线交错带 中下部分成树将更多资源投入径向生长, 转为保守 性策略。综上所述, 两个样地内的冷杉种群均呈现 出稳定状态, 在一定程度上为全球变暖背景下树线 的进一步爬升提供了潜在可能性。

\section{3 高山树线时空动态与空间分布格局}

种群空间分布格局是由多种生态学过程共同作 用形成的，不同的分布格局表达了物种不同的生长 策略以及对环境的响应机制。通常情况下，空间分 布格局与空间尺度有密切联系(张金屯, 1998)。此外, 种群空间分布格局与其龄级结构也有一定相关性, 解传奇等(2015)对色季拉山的急尖长苞冷杉(Abies georgei var. smithii)的研究表明, 幼树和中树在小尺 度上均呈聚集分布, 而大树则呈均匀分布。有学者 
指出地形因子也会影响种群空间分布格局, 兰国玉 等(2008)发现坡向会改变光照、温度及土壤养分水 分等因子，导致局部小环境发生改变从而影响植物 生长, 进而影响种群的分布格局。本研究中, 折多山 峨眉冷杉种群在小尺度上呈现聚集分布, 且随着尺 度变大聚集度逐渐增强。在小尺度上呈聚集分布主 要是由于种子扩散限制, 种子在母株周围萌发产生 的小树呈现聚集分布, 龄级结构中峨眉冷杉幼树的 数量占较大比例在一定程度上印证了这点。树木种 群的聚集分布将有助于增强种群的种间竞争力, 并 且利于种内个体相互庇护以抵御严酷的外界环境, 同时提高了资源利用效率(李国春等, 2017)。在更大 的尺度上峨眉冷杉种群呈明显的聚集分布, 这与解 传奇等(2015)的研究结果不太一致, 这主要与生境 异质性以及研究对象的差异有关。该样地内土壤厚 度不均一且较薄, 甚至存在岩石裸露的区域, 达不 到树木的立地条件, 种群更新过程中树木会选择环 境相对较好的区域, 从而使其分布的聚集程度有所 加强。类似于折多山的成因, 剪子弯山的鳞皮冷杉 种群在小尺度上也呈现聚集状态。然而随着尺度的 增大, 种群逐渐呈现随机分布, 这与大多数研究结 果相似(张金屯, 1998; 杨华等, 2014)。资源有限性导 致种内和种间竞争加强, 造成树种的自疏或它疏, 这可能是使种群聚集度下降的主要因素; 另外, 该 样地或受到人为干扰, 导致种群数量有所下降, 在 大尺度上表现为树种密度降低且分布随机化。综上 所述, 空间格局分析表明局部生长环境是影响冷杉 种群分布的主要因素。

在全球气候变化背景下, 高山生态系统相比于 其他生态系统对气候变化更为敏感。目前, 尽管已 有大量研究结果表明气候变暖导致了高山树线的明 显爬升(Luckman \& Kavanagh, 2000; Kullman, 2001; 王亚锋等, 2017), 但Harsch等(2009)认为, 全球变暖 趋势下 $47 \%$ 的树线位置未发生明显变化, 这说明高 山树线对气候变化的敏感性差异较大。在本研究中, 我们发现近 10 年内, 高山树线及树种线位置均无显 著变化, 而树种密度存在小幅度升高, 与Liang等 (2011)及Klasner和Fagre (2002)得到的研究结果类似, 树种密度增加主要由温度上升所引起, 并且树种密 度对气候变暖的响应比树线更为敏感(Wang, 2006; van Bogaert, 2011)。树线及树种线在10年内保持稳 定是由多种因素导致的。首先, 温度是影响高海拔
地区树木生长的重要因素, 其中冬夏两季的温度更 是影响树线变化的关键因素(Lloyd \& Fastie, 2003)。 冬季低温会使树木组织受到不可逆的损害, 也会导 致树木木质部水分形成冰晶, 阻碍水分的吸收及在 树干系统中的运输, 同时冻融事件的发生会导致植 物栓塞, 这些现象都将严重影响树木的正常生长 (Mayr \& Charra-Vaskou, 2007; Körner, 2017)。时间序 列年平均气温的分析结果发现, 康定及雅江地区 58 年来气温存在明显上升趋势, 也许一定程度上缓解 了树线处树木受到的低温胁迫, 但低温对树线爬升 的限制作用依然存在。其次, 降水与树线动态具有 一定联系。Gaire等(2014)对树线树种西藏冷杉(Abies spectabilis)的研究表明, 其更新和生长与夏季降水 量存在正相关关系。在本研究中, 研究区域降水均 存在微弱的降低趋势, 可能不利于树线的进一步爬 升。再者, 种间关系及人为干扰对树线及树种线的 位置具有一定影响, Wang等(2012)指出在人为干扰 打破树线种群与高密度灌从间的平衡后, 树线位置 具有上升的可能性, 本研究中样地高海拔坡位上的 高密度杜鹃灌从在一定程度上阻碍了主要依靠风力 及重力传播的树木种子的扩散过程。另外, 不适宜 生长的立地环境也是树线及树种线爬升的潜在限制 因素。与前 20 年的情况相比, 两个样地的树种密度、 树线及树种线位置均明显上升, 这些现象的发生是 由多种因素共同造成的, 比如生长环境, 种间关系 及降水等, 而气候变暖是本研究中 20 年内树线发生 变化的主要因素, 已有大量的研究表明过去数十年 的气候变暖导致了树线位置的上升(Luckman \& Kavanagh, 2000; Kullman, 2001), 同时树种密度随 气候变暖而增加的现象也得到了大量研究的支持 (Camarero \& Gutierrez, 2004)。另外, 值得注意的是 两个样地的树线位置在 10 年的时间尺度上均无明显 变化, 而在 20 年的时间尺度上则发生了显著的爬 升。这可能与以下几点原因有关: 首先, 在前 10 年 树线及树种线已经到达了较高的海拔位置, 在该海 拔以上土壤厚度、养分含量逐渐下降, 甚至存在岩 石裸露的区域, 树木生长得不到足够的养分支持, 生长速度较低; 其次, 目前两个样带内的树木及伴 生灌从的数量较 20 年前有所增加, 种内和种间竞争 较之前亦有提高, 在一定程度上对树线的提升造成 了阻碍; 再者, 树线变化的滞后性可能导致10年前 树线变化在今后的 10 年或更长时间才能有所体现。 
此外, 尽管总体上气候是变暖的, 但短期的寒冷事 件还会造成树木的调亡(Kullman，1993; Körner, 2017)。从国家政策层面来看, 20 年前正值天然林保 护工程开始实施阶段, 禁牧禁伐使得干扰降低, 天 然树线/林线的上升较为明显, 而10年前与近期相 比树线位置已相对趋于稳定。MacDonald等(1998) 曾指出树线海拔上升、种群密度增加和树木生长加 快是树线响应气候变暖的主要方式。前两种响应方 式在本文中都有所体现, 而树木生长速率变化有待 进一步通过树芯生长分析来研究。综上所述, 较大 时空尺度上气候变暖是导致树线上升的主要因素, 而在小时空尺度上树线变化受温度、降水、人为干 扰及生长环境等因素的共同影响。

\section{4 结论}

气候变暖是大尺度上树线上升的主要驱动因素, 局部树线的变化则与其生长的局地环境密切相关。 树线动态变化是个复杂的生态学过程, 其中常伴随 着树线种群生态学特征的改变。(1)折多山的峨眉冷 杉种群和剪子弯山的鳞皮冷杉种群具有相对稳定的 种群结构, 其龄级结构分别为反“J”形和双峰形。(2) 在小尺度上由于种子扩散限制, 两个样地的树种均 呈聚集分布; 在大尺度上, 生境异质性增强了折多 山样地的种群聚集, 而资源有限性以及种内或种间 竞争增强导致剪子弯山的种群聚集度下降, 呈现出 随机分布的状态。(3)树种的基径及树高均随海拔的 升高而降低, 基径与树高的相关生长关系在高海拔 坡位呈显著的异速生长关系, 随海拔的下降逐渐呈 现等速生长关系。(4)相比于 20 年前, 两处的树种线 和树线位置均发生了明显的上移, 树木个体数亦显 著增加。由此可见, 对于树线种群生态学特征以及 树线时空动态两方面的研究, 有助于丰富树线对全 球气候变暖响应机制的理解, 加深对高山生命带生 态格局和过程的认识。

\section{参考文献}

Bai DZ (2012). The Impact Factors of Growth and Regeneration of Picea crassifolia Growing at Timberline in The Qilian Mountains. PhD dissertation, Chinese Academy of Forestry, Beijing. [白登忠 (2012). 祁连山青海云杉林线 树木生长、更新的影响因素研究. 博士学位论文, 中国 林业科学研究院, 北京.]

Batllori E, Blanco-Moreno JM, Ninot JM, Gutierrez E, Carrillo E (2009). Vegetation patterns at the alpine treeline ecotone: The influence of tree cover on abrupt change in species composition of alpine communities. Journal of Vegetation Science, 20, 814-825.

Camarero JJ, Gutierrez E (2004). Pace and pattern of recent treeline dynamics, response of ecotones to climatic variability in the Spanish Pyrenees. Climatic Change, 63, 181-200.

Cheng W, Luo P, Wu N (2005). Ecological characteristics of minjiang fir (Abies faxoniana Rehd. et Wild) population near timberline on upper Min River. Chinese Journal of Applied and Envirnmental Biology, 11, 300-303. [程伟, 罗鹏, 吴宁 (2005). 岷江上游林线附近怅江冷杉种群 (Abies faxoniana Rehd. et Wild)的生态学特点. 应用与 环境生物学报, 11, 300-303.]

Condit R, Ashton PS, Baker P, Bunyavejchewin S, Gunatilleke S, Gunatilleke N, Hubbell SP, Foster RB, Itoh A, Lafrankie JV, Lee HS, Losos E, Manokaran N, Sukumar R, Yamakura T (2000). Spatial patterns in the distribution of tropical tree species. Science, 288, 1414-1418.

Dai JH, Cui HT (1999). A reviewon the studies of alpine timberline. Scientia Geographica Sinica, 19(3), 52-58. [戴君 虎, 崔海亭 (1999). 国内外高山林线研究综述. 地理科 学, 19(3), 52-58.]

Falster DS, Westoby M (2003). Plant height and evolutionary games. Trends in Ecology \& Evolution, 18, 337-343.

Gaire NP, Koirala M, Bhuju DR, Borgaonkar HP (2014). Treeline dynamics with climate change at the Central Nepal Himalaya. Climate of the Past, 10, 1277-1290.

Gao J, Wang JN, Xu B, Xie Y, He JD, Wu Y (2016). Plant leaf traits, height and biomass partitioning in typical ephemerals under different levels of snow cover thickness in an alpine meadow. Chinese Journal of Plant Ecology, 40, 775-787. [高景, 王金牛, 徐波, 谢雨, 贺俊东, 吴彦 (2016). 不同雪被厚度下典型高山草地早春植物叶片性 状、株高及生物量分配的研究. 植物生态学报, 40 , 775-787.]

Harsch MA, Hulme PE, Mcglone MS, Duncan RP (2009). Are treelines advancing? A global meta-analysis of treeline response to climate warming. Ecology Letters, 12, 1040-1049.

IPCC (Intergovernmental Panel on Climate Change) (2014). Contribution of Working Group II to the Fifth Assessment Report of the Intergovernmental Panel on Climate Change. Cambridge University Press, Cambridge, UK.

Jin HJ, Ma QL, Zhang DK, Liu YJ, Yuan HB (2012). Analysis on typical shrub plant community characteristics and quantitative characteristics in Ulanbuh desert. Acta Botanica Boreall-Occidentalia Sinica, 32, 579-588. [靳虎甲, 马全 林, 张德魁, 刘有军, 袁洪波 (2012). 乌兰布和沙漠典 型灌木群落结构及数量特征. 西北植物学报, 32 , 579-588.]

Kim JW, Lee JS (2015). Dynamics of alpine treelines: Positive feedbacks and global, regional and local controls. Journal of Ecology and Environment, 38, 1-14.

Klasner FL, Fagre DB (2002). A half century of change in alpine treeline patterns at Glacier National Park, Montana, 
USA. Arctic Antarctic and Alpine Research, 34, 49-56.

Knowles P, Grant MC (1983). Age and size structure analyses of engelmann spruce, ponderosa pine, lodgepole pine, and limber pine in Colorado. Ecology, 64, 1-9.

Körner C (1998). A re-assessment of high elevation treeline positions and their explanation. Oecologia, 115, 445-459.

Körner C (2003). Alpine Plant Life. 2nd edn. Springer, Berlin.

Körner C (Translated by Wu N, Shi PL, Yi SL, Wang JN) (2017). Alpine Treelines. Publishing House of Electronics Industry, Beijing. [吴宁, 石培礼, 易绍良, 王金牛 (译) (2017). 高山树线一一全球高海拔树木生长上线的功能 生态学. 电子工业出版社, 北京.]

Körner C, Paulsen J (2004). A world-wide study of high altitude treeline temperatures. Journal of Biogeography, 31, 713-732.

Kullman L (1993). Tree timit dynamics of Betula pubescens ssp. tortuosa in relation to climate variability: Evidence from Central Sweden. Journal of Vegetation Science, 4, 765.

Kullman L (2001). 20th century climate warming and tree-limit rise in the southern Scandes of Sweden. AMBIO, 30, $72-80$.

Lan GY, Hu YH, Cao M, Zhu H, Wang H, Zhou SS, Deng XB, Cui JY, Huang JG, Liu LY, Xu HL, Song JP, He YC (2008). Establishment of Xishuangbanna tropical forest dynamics plot: Species compositions and spatial distribution patterns. Chinese Journal of Plant Ecology (Chinese Version), 32，287-298. [兰国玉，胡跃华，曹敏，朱华, 王洪, 周仕顺, 邓晓保, 崔景云, 黄建国, 刘林云, 许海 龙, 宋军平, 何有才 (2008). 西双版纳热带森林动态监 测样地一一树种组成与空间分布格局. 植物生态学报, 32, 287-298.]

Li GC, Song HD, Li Q, Bu SH (2017). Spatial point pattern analysis of main trees and flowering Fargesia qinlingensis in Abies fargesii forests in Mt. Taibai of the Qinling Mountains, China. Chinese Journal of Applied Ecology, 28, 3487-3493. [李国春, 宋华东, 李琦, 卜书海 (2017). 太白山巴山冷杉林主要树种与开花秦岭箭竹的空间点 格局分析. 应用生态学报, 28, 3487-3493.]

Li LP, Mohamma A, Wang XP (2011). Study on relationship between height and DBH of mountain coniferous forests in Xinjiang. Arid Zone Research, 28(1), 47-53. [李利平, 安 尼瓦尔・买买提, 王襄平 (2011). 新疆山地针叶林乔木 胸径-树高关系分析. 干旱区研究, 28(1), 47-53.]

Liang EY, Leuschner C, Dulamsuren C, Wagner B, Hauck M (2016). Global warming-related tree growth decline and mortality on the north-eastern Tibetan Plateau. Climatic Change, 13, 163-176.

Liang EY, Wang YF, Eckstein D, Luo TX (2011). Little change in the fir tree-line position on the southeastern Tibetan Plateau after 200 years of warming. New Phytologist, 190, 760-769.

Liu XD, Chen BD (2000). Climatic warming in the Tibetan Plateau during recent decades. International Journal of Climatology, 20, 1729-1742.
Lloyd AH, Fastie CL (2002). Spatial and temporal variability in the growth and climate response of treeline trees in Alaska. Climate Change, 52, 481-509.

Lloyd AH, Fastie CL (2003). Recent changes in treeline forest distribution and structure in interior Alaska. Ecoscience, 10, 176-185.

Luckman B, Kavanagh T (2000). Impact of climate fluctuations on mountain environments in the Canadian Rockies. AMBIO, 29, 371-380.

MacDonald GM, Szeicz JM, Claricoates J, Dale KA (1998). Response of the central Canadian treeline to recent climatic changes. Annals of the Association of American Geographers, 88, 183-208.

Mayr S, Charra-Vaskou K (2007). Winter at the alpine timberline causes complex within-tree patterns of water potential and embolism in Picea abies. Physiologia Plantarum, 131, 131-139.

Niklas KJ (2005). Modelling below- and above-ground biomass for non-woody and woody plants. Annals of Botany, 95, 315-321.

Pelissier R, Goreaud F (2015). Ads package for R: A fast unbiased implementation of the $\mathrm{k}$-function family for studying spatial point patterns in irregular-shaped sampling windows. Journal of Statistical Software, 63, 1-18.

Ran F, Liang YM, Yang Y, Yang Y, Wang GX (2014). Spatialtemporal dynamics of an Abies fabri population near the alpine treeline in the Yajiageng area of Gongga Mountain, China. Acta Ecologica Sinica, 34, 6872-6878. [业飞, 梁 一鸣, 杨燕, 杨阳, 王根绪 (2014). 贡嘎山雅家埂峨眉 冷杉林线种群的时空动态. 生态学报, 34, 6872-6878.]

Ripley BD (1977). Modeling spatial patterns. Journal of the Royal Statistical Society Series B-Methodological, 39, 172-212.

Shi CM, Masson-Delmotte V, Daux V, Li ZS, Carre M, Moore JC (2015). Unprecedented recent warming rate and temperature variability over the east Tibetan Plateau inferred from alpine treeline dendrochronology. Climate Dynamics, 45, 1367-1380.

Shi JY, Han HR, Cheng XQ, Dong LL, Tian HX, Cai MK, Kang FF (2017). Age structure and dynamics of Pinus tabuliformis population in the Liaoheyuan Nature Reserve of Hebei Province. Chinese Journal of Ecology, 36, 1808-1814. [矢佳昱, 韩海荣, 程小琴, 董玲玲, 田慧霞, 蔡锰柯, 康峰峰 (2017). 河北辽河源自然保护区油松种 群年龄结构和种群动态. 生态学杂志, 36, 1808-1814.]

Stevens GC, Fox JF (1991). The causes of treeline. Annual Review of Ecology and Systematics, 22, 177-191.

Stewart GH, Rose AB (1990). The significance of life-history strategies in the developmental history of mixed beech (nothofagus) forests, New-Zealand. Vegetatio, 87, 101-114.

van Bogaert R, Haneca K, Hoogesteger J, Jonasson C, de Dapper M, Callaghan TV (2011). A century of tree line changes in sub-Arctic Sweden shows local and regional variability and only a minor influence of 20th Century climate warming. Journal of Biogeography, 38, 907-921.

www.plant-ecology.com 
Wang T, Zhang QB, Ma KP (2006). Treeline dynamics in relation to climatic variability in the central Tianshan Mountains, northwestern China. Global Ecology and Biogeography, 15, 406-415.

Wang YF, Julio Camarero J, Luo TX, Liang EY (2012). Spatial patterns of smith fir alpine treelines on the south-eastern Tibetan Plateau support that contingent local conditions drive recent treeline patterns. Plant Ecology \& Diversity, $5,311-321$

Wang YF, Liang EY (2012). A review on progresses in treeline dynamics and climate change. Journal of Earth Environment, 3, 855-861. [王亚锋, 梁尔源 (2012). 树线波动与 气候变化研究进展. 地球环境学报, 3, 855-861.]

Wang YF, Liang EY, Lu XM, Zhu HF, Piao SL, Zhu LP (2017). Are treelines advancing in response to climate warming on the Tibetan Plateau? Chinese Journal of Nature, 39，179-183. [王亚锋, 梁尔源, 芦晓明, 朱海峰, 朴世龙, 朱立平 (2017). 气候变暖会使青藏高原树线一 直上升吗? 自然杂志, 39, 179-183.]

Warton DI, Duursma RA, Falster DS, Taskinen S (2012). Smatr 3-An R package for estimation and inference about allometric lines. Methods in Ecology and Evolution, 3, 257-259.

Warton DI, Wright IJ, Falster DS, Westoby M (2006). Bivariate line-fitting methods for allometry. Biological Reviews, 81, 259-291.

Wilmking M, Juday GP, Barber VA, Zald HSJ (2004). Recent climate warming forces contrasting growth responses of white spruce at treeline in Alaska through temperature thresholds. Global Change Biology, 10, 1724-1736.

Wong MH, Duan CQ, Long YC, Luo YM, Xie GQ (2010). How will the distribution and size of subalpine Abies georgei forest respond to climate change? A study in northwest Yunnan, China. Physical Geography, 31, 319-335.

Xie CQ, Tian MX, Zhao ZR, Zheng WL, Wang GY (2015). Spatial point pattern analysis of Abies georgei var. smithii in forest of Sygera Mountains in southeast Tibet, China.
Chinese Journal of Applied Ecology, 26, 1617-1624. [解 传奇, 田民霞，赵忠瑞，郑维列，王国严 (2015). 西藏 色季拉山急尖长苞冷杉种群点格局分析. 应用生态学 报, 26, 1617-1624.]

Xie ZQ, Chen WL, Lu P, Hu D (1999). The demography and age structure of the endangered plant population of $\mathrm{Ca}$ thaya argyrophylla. Acta Ecologica Sinica, 19, 523-528. [谢宗强, 陈伟烈, 路鹏, 胡东 (1999). 濒危植物银杉的 种群统计与年龄结构. 生态学报, 19, 523-528.]

Yang H, Li YL, Shen L, Kang XG, Yue G, Wang Y (2014). Spatial distribution patterns of seedling and sapling in a spruce-fir forest in the Changbai Mountains area in northeastern China. Acta Ecologica Sinica, 34, 7311-7319. [杨 华, 李艳丽, 沈林, 六新刚, 岳刚, 王妍 (2014). 长白山 云冷杉林幼苗幼树空间分布格局及其更新特征. 生态 学报, 34, 7311-7319.]

Yang XD, Yan ER, Zhang ZH, Sun BW, Huang HX, Arshad A, Ma WJ, Shi QR (2013). Tree architecture of overlapping species among successional stages in evergreen broadleaved forests in Tiantong region, Zhejiang Province, China. Chinese Journal of Plant Ecology, 37, 611-619. [杨晓东, 阎恩荣, 张志浩, 孙宝伟, 黄海侠, Arshad A, 马文济, 史青茹 (2013). 浙江天童常绿阔叶林演替阶段 共有种的树木构型. 植物生态学报, 37, 611-619.]

Zhang JT (1998). Analysis of spatial point pattern for plant species. Acta Phytocologica Sinica, 22, 57-62. [张金屯 (1998). 植物种群空间分布的点格局分析. 植物生态学 报, 22, 57-62.]

Zhang PJ, Qing H, Zhang L, Xu YD, Mu L, Ye RH, Qiu X, Chang H, Shen HH, Yang J (2017). Population structure and spatial pattern of Caragana tibetica communities in Nei Mongol shrub-encroached grassland. Chinese Journal of Plant Ecology, 41, 165-174. [张璞进, 清华, 张雷, 徐 延达, 木兰, 晔薷罕, 邱晓, 常虹, 沈海花, 杨劼 (2017). 内蒙古灌丛化草原毛刺锦鸡儿种群结构和空间 分布格局. 植物生态学报, 41, 165-174.]

责任编委: 石培礼 责任编辑: 李 敏

附录I 康定及雅江地区1月和7月温度变化。

Supplement I The variation of temperature of the Kangding and Yajiang in January and July. http://www.plant-ecology.com/fileup/PDF/cjpe.2018.0082-s1.pdf

附录II 康定及雅江地区1月和7月降水量变化。

Supplement II The variation of precipitation of the Kangding and Yajiang in January and July. http://www.plant-ecology.com/fileup/PDF/cjpe.2018.0082-s2.pdf

附录III 康定及雅江地区58年的温度和降水量变化。 Supplement III The variation of temperature and precipitation in the Kangding and Yajiang during the past 60 years (from 1960 to 2017 AD).

http://www.plant-ecology.com/fileup/PDF/cjpe.2018.0082-s3.pdf 